\title{
Erratum to: Governance and Sustainability of Responsible Research and Innovation Processes
}

Fernando Ferri, Ned Dwyer, Saša Raicevich, Patrizia Grifoni, Husne Altiok, Hans Thor Andersen, Yiannis Laouris and Cecilia Silvestri

\section{Erratum to:}

F. Ferri et al., Governance and Sustainability of Responsible Research and Innovation Processes, SpringerBriefs in Research and Innovation Governance, https://doi.org/10.1007/978-3-319-73105-6

Chapters 1 and 3 have now been published open access under a CC BY 4.0 license. The original book has been updated with the changes. 